\title{
Propriedades tecnológicas do tijolo solo-cimento vazado de 2 furos
}

\author{
Felipe Pinheiro Teixeira ${ }^{1}$ \\ Thaís Guedes Machado \\ Neilton Paixão de Jesus Junior ${ }^{1}$ (1) \\ Simone Pereira Taguchi Borges ${ }^{1}$ \\ Rosinei Batista Ribeiro ${ }^{2}$ \\ Luiz Antônio Borges Júnior ${ }^{1}$
}

\section{Resumo}

O tijolo solo-cimento possui baixo custo de produção, durabilidade, dispensa o processo de queima, sendo considerado por alguns autores tijolo ecológico. O solo utilizado apresentou tamanho de partícula entre 0,2-80 $\mu \mathrm{m}$, fases cristalinas de quartzo e caulinita, limites de liquidez e plasticidade de $44 \%$ e $30 \%$ respectivamente. Os pós de solo:areia:cimento CP-V ARI foram misturados com proporção 6:2:1, adicionado água para adquirir plasticidade, conformados por prensagem uniaxial ( 2 toneladas), obtendo corpos de prova cilíndricos de $\$ 50 \times 100 \mathrm{~mm}$, seguido de cura em água durante 7 dias. Foram submetidos ao ensaio de compressão simples, obtendo média de 2,75 MPa. Tijolos solo-cimento de dois furos, com mesma composição, foram conformados em prensa hidráulica (6 toneladas), com dimensões de 250x126x69 mm, realizados ensaios de absorção de água e compressão simples, obtendo médias de $18,95 \%$ e 2,09 MPa, respectivamente. Ambos apresentam resistência mecânica similar ao estimado na NBR 8492, porém valor menor para o tijolo, possivelmente pela influência da geometria e efeito do capeamento.

Palavras chave: Tijolo; Solo-cimento; Compressão; Absorção de água.

\section{Technological properties of soil-cement brick with 2 holes}

\begin{abstract}
The soil-cement brick has a low production cost, durability, no burning process, and is considered an ecological brick. The soil used presented particle size between $0.2-80 \mu \mathrm{m}$, crystalline phases of quartz and kaolinite, liquidity and plasticity limities of $44 \%$ and $30 \%$ respectively. The soil powders:sand:CP-V ARI cement were mixed with 6:2:1 ratio, added water to acquire plasticity, formed by uniaxial pressing ( 2 tons), obtaining cylindrical test pieces of $\phi 50 \times 100$ $\mathrm{mm}$, followed by curing in water for 7 days. They were submitted to the simple compression test, obtaining an average of 2.75 MPa. Two-hole soil-cement bricks, with the same composition, were pressed in a hydraulic press (6 tons), with dimensions of 250x126x69 mm, performed water absorption and simple compression tests, obtaining averages of $18.95 \%$ and 2.09 MPa, respectively. Both have mechanical resistance within the one estimated in NBR 8492, but smaller value for the brick, possibly due to the influence of the geometry and overlay effect.
\end{abstract}

Keywords: Brick; Soil-cement; Compression; Water absorption.

\section{Introdução}

A construção civil no Brasil é responsável por 14\% do Produto Interno Bruto - PIB (2012) e é considerado o setor de maior geração de resíduos. O Conselho Brasileiro de Construção Sustentável (CBCS) estima que com o crescimento populacional e a demanda na construção civil os problemas ambientais se agravem [1].
O déficit habitacional é uma realidade e novos sistemas construtivos são estudados como alternativas de métodos e de materiais, visando: redução de custos, menor impacto ambiental, desenvolvimento sustentável e reaproveitamento de material [2,3]. Neste sentido o tijolo solo-cimento vem ganhando espaço mercadológico, sendo chamado de tijolo ecológico.

${ }^{1}$ Departamento de Engenharia Química - DEQ, Universidade Federal Rural do Rio de Janeiro - UFRRJ, Seropédica, RJ, Brasil.

${ }^{2}$ Centro Universitário Teresa D'Ávila, Lorena, SP, Brasil.

*Autor correspondente: neiltonpjj@gmail.com

2176-1523 (C) 2021. Teixeira et al. Publicado pela ABM. Este é um artigo publicado em acesso aberto (Open Access) sob a licença Creative Commons Attribution, que permite uso, distribuição e reprodução em qualquer meio, sem restrições desde que o trabalho original seja Commons Attribution,
corretamente citado. 
No tijolo de solo-cimento é utilizado solo, cimento e água, devidamente homogeneizados e, posteriormente, compactados em prensas manuais ou hidráulicas. O solo é o componente com maior volume na produção do tijolo. O cimento, por outro lado, contribuí com quantidades bem menores, variando de $5 \%$ a $10 \%$ da massa do solo, que é o suficiente para estabilizá-lo e conferir-lhe as propriedades de resistência desejadas [4]. Rolim apud Lima [1] destaca a necessidade de se conhecer os materiais utilizados, principalmente o solo (matéria-prima base), que deve ser física e mecanicamente caracterizado.

O uso de tijolos solo-cimento apresenta caraterísticas positivas, como seu formato, possibilitando o encaixe um sobre o outro, possui furos em sua geometria que permitem a passagem de vigas e tubulações, economiza o uso de argamassa e concreto, reduzindo também a geração de entulhos, que atualmente é considerado um grave problema [2].

Comparando os tijolos solo-cimento com os tijolos convencionais de cerâmica queimada, eles são resistentes mecanicamente, podem apresentar durabilidade até 6 vezes superior ao convencional, possuem bom índice de permeabilidade e bom desempenho na resistência à compressão [2].

Este trabalho visa a comparação dos resultados de resistência à compressão de corpos de prova cilíndricos com os tijolos vazados de 2 furos, ambos com mesma composição, com o intuito de identificar se o formato da peça e as etapas de preparação influenciam no resultado.

\section{Materiais e métodos}

O solo utilizado neste trabalho é proveniente do Vale do Paraíba/SP e foi cedido pela empresa Minerais do Rio Doce. O solo presenta característica silto argilosa e origem caulinítica. A areia é do tipo lavada, proveniente da região de Piranema/RJ. O cimento utilizado neste trabalho foi o CP-V ARI, marca Votoran, que é um cimento com alta resistência inicial, o que facilita a desmoldagem dos corpos de prova.

Primeiramente foi produzido corpos de prova cilíndricos conforme a norma ABNT NBR 12024 [5], com o intuito de avaliar a resistência à compressão utilizando a norma NBR 12025 [6]. Posteriormente, tijolos vazados de solo-cimento foram produzidos conforme a norma NBR 10833 [7], capeados conforme a NBR 8492 [8] e realizado o ensaio de compressão conforme NBR 8491 [9].

A resistência à compressão dos corpos de prova cilíndricos foi comparada com a dos tijolos vazados, ambos produzidos com as mesmas composições e tempo de cura, com o intuito de avaliar se a geometria e etapa de capeamento influenciariam nos resultados.

\subsection{Caracterização das Matérias-primas}

O solo foi seco em estufa com temperatura em torno de $110^{\circ} \mathrm{C}$ até que mantivesse seu peso constante. Foi realizada a análise granulométrica em peneiras de $0,318 \mathrm{~mm}, 0,037 \mathrm{~mm}$ e $0,030 \mathrm{~mm}$.

O limite de liquidez (LL) do solo foi realizado seguindo a norma ABNT NBR 6459:16 [10], que exige a utilização do aparelho de Casagrande, um cinzel e um gabarito. O limite de plasticidade (LP) do solo foi realizado seguindo especificações da norma ABNT NBR 7180:16 [11]. A partir dos resultados de limite de liquidez (LL) e limite de plasticidade (LP) obteve-se o índice de plasticidade (IP), pela Equação 1. O valor de IP mostra a porcentagem de água necessária para que o solo consiga se comportar plasticamente.

$$
I P=L L-L P
$$

O ensaio da difração de raios $\mathrm{X}$ do solo e do cimento foi realizado no Difratômetro da marca Panalytical, modelo Empyre, com tubo de cobre, $2 \theta=5-80^{\circ}$ e passo angular 0,002 . A amostra foi previamente triturada e peneirada, deixando com a forma de pó bem fino com partículas menores que $150 \mu \mathrm{m}$. Os picos foram identificados por comparação com as fichas JCPDS, utilizando o programa XPert High Score Plus e para o tratamento dos dados foi utilizado o OringPro 8.

\subsection{Preparação dos corpos de prova e ensaio de compressão simples}

A mistura solo:areia:cimento foi feita manualmente, até aparência uniforme, na proporção 6:2:1, respectivamente. Foi adicionado água em pequenas quantidades para dar plasticidade à mistura, utilizando o teste de empírico de compressão manual. É considerado a umidade ideal quando consegue-se separar as duas partes sem esfarelar e sem grudar nas mãos.

Os 5 corpos de prova cilíndricos, com $100 \mathrm{~mm}$ de comprimento e $50 \mathrm{~mm}$ de diâmetro, foram preparados seguindo as especificações da norma ABNT NBR 12024: Solo-cimento - Moldagem e cura de corpos de prova cilíndricos - Procedimento [5]. A conformação foi obtida por prensagem uniaxial, em prensa hidráulica com carga de 1 tonelada, utilizando um pistão/molde desenvolvido com tubo PVC e pistão de madeira.

Após a cura por 7 dias, com umidade relativa de aproximadamente $95 \%$, os CPs foram imersos em recipiente com água durante 4 horas, secados com pano úmido e, imediatamente, foram medidas suas dimensões para ser realizado o ensaio de compressão simples conforme a norma ABNT NBR 12025: solo-cimento - Ensaio de compressão simples de corpos de prova cilíndricos - Métodos de ensaio [6]. De acordo com essa norma, o ensaio mecânico em corpo de prova é qualitativo e não especifica um valor típico de resistência à compressão.

O carregamento do ensaio de compressão simples foi com deformação controlada de aproximadamente $1 \mathrm{~mm} / \mathrm{min}$, sendo a carga inicial aplicada de $50 \mathrm{kgf} / \mathrm{s}$. A resistência à compressão simples foi calculada pela média aritmética das 
resistências individuais de cinco corpos de prova, nas quais foram consideradas carga de ruptura e área útil de aplicação de carga, conforme Equação 2.

$$
f t=\frac{F}{S}
$$

Onde: $f t ̦=$ resistência a compressão simples $(\mathrm{MPa}) ; \mathrm{F}=$ força de ruptura do corpo de prova $(\mathrm{N}) ; \mathrm{S}=$ área de aplicação da carga $\left(\mathrm{mm}^{2}\right)$.

\subsection{Preparação dos tijolos solo-cimento, absorção de água e resistência à compressão}

O processamento do tijolo solo-cimento foi realizado conforme a norma ABNT NBR 10833:12 [7] que estabelece os requisitos e procedimento para fabricação em prensa hidráulica.

O solo, areia e o cimento foram misturados na proporção 6:2:1, em betoneiras por 5-10 minutos. Em seguida, foi adicionado água, para garantir que a mistura tivesse consistência adequada para a etapa de prensagem. A quantidade de água na mistura foi estimada pelo teste empírico da compressão manual.

A mistura foi transferida para um molde metálico de uma prensa hidráulica Eco Máquinas, da empresa Eco Real, obtendo tijolos no formato vazados, com dimensões de 250x126x69 mm. Os tijolos solo-cimento foram submetidos a cura em água durante 7 dias, análise dimensional, ensaio de absorção de água e ensaio de resistência à compressão simples. Foram produzidos 10 corpos de prova, sendo 3 usados para ensaio de absorção de água e 7 para ensaio de compressão.

Para o ensaio de absorção de água os tijolos foram pesados, seguiram para estufa por 6 horas e novamente pesados; esse processo foi repetido até garantir massa constante, conforme indicado pela NBR 8492/2012 [8]. Os tijolos foram submersos em água por 24 horas e, após a imersão, foram secos com pano úmido e pesados, sendo essa a massa saturada do tijolo. A porcentagem de absorção de água das amostras foi calculada conforme a Equação 3.

$$
A=\frac{m 2-m 1}{m 1} \times 100
$$

Onde: A é a absorção de água; $\mathrm{m} 1$ é a massa de tijolo seco em estufa (g); e m2 é a massa do tijolo saturado (g).

Segundo a norma ABNT NBR 8491/2012 [9], o valor médio da de absorção de água dos tijolos não devem ser superiores a $20 \%$ e não devem apresentar valores individuais superiores a $22 \%$.

Os tijolos para ensaio de compressão foram cortados perpendicularmente ao meio, e capeados com argamassa conforme a ABNT NBR 8492:12 [8]. Desta forma, as duas metades dos tijolos foram assentadas com argamassa e recobertas acima e abaixo para deixar as superfícies totalmente planas, conforme Figura 1. Após o endurecimento da argamassa (no mínimo de 12 horas entre cada etapa), os corpos de prova foram imersos em um recipiente com água, onde permaneceram por 6 horas, sendo retirados e enxugados superficialmente com um pano úmido e, imediatamente, realizado o ensaio de compressão em máquina universal de ensaios, marca CONTRECO UMC 300, com capacidade de carga até 30 toneladas. A resistência à compressão foi calculada utilizado a Equação 2, conforme descrito anteriormente.

Segundo a norma ABNT NBR 8491/2012 [9], o valor médio da resistência a compressão simples dos tijolos deve ser no mínimo de $2 \mathrm{MPa}\left(20 \mathrm{kgf} / \mathrm{cm}^{2}\right)$, de modo que nenhum desses valores individuais estejam abaixo de 1,7 MPa.

\section{Resultados e discussão}

\subsection{Características das matérias-primas}

A Figura 2 apresenta o limite de liquidez (LL) do solo. Em nenhuma das quantidades de água utilizada nos ensaios a ranhura obtida pelo cinzel se fechou com 25 golpes, logo o valor de umidade referente a essa quantia foi obtido por uma interpolação dos dados, obtendo o valor de $44 \%$ como limite de liquidez do solo.

O limite de plasticidade obtido pela umidade na conformação de rolinhos $10 \times 3 \mathrm{~mm}$ foi de $30 \%$. Usando a Equação 1, obtemos o índice de plasticidade do solo no valor de $14 \%$.
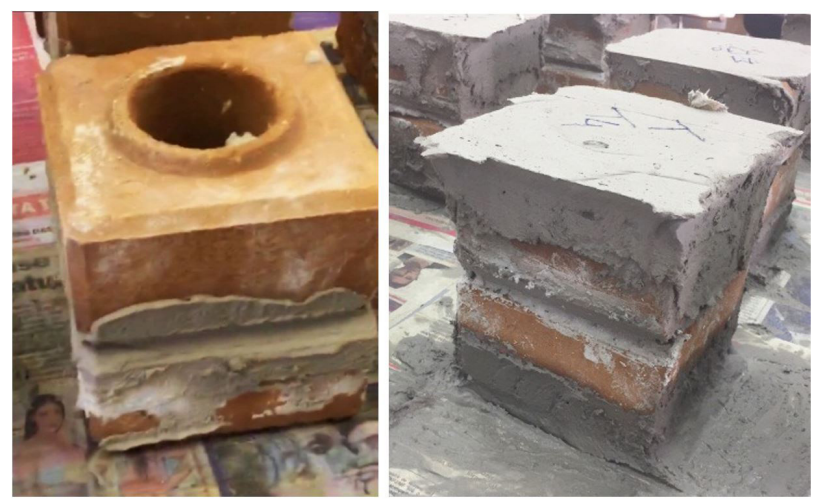

Figura 1. (a) Meio tijolo assentado com argamassa; (b) Capeamento superior e inferior com argamassa.

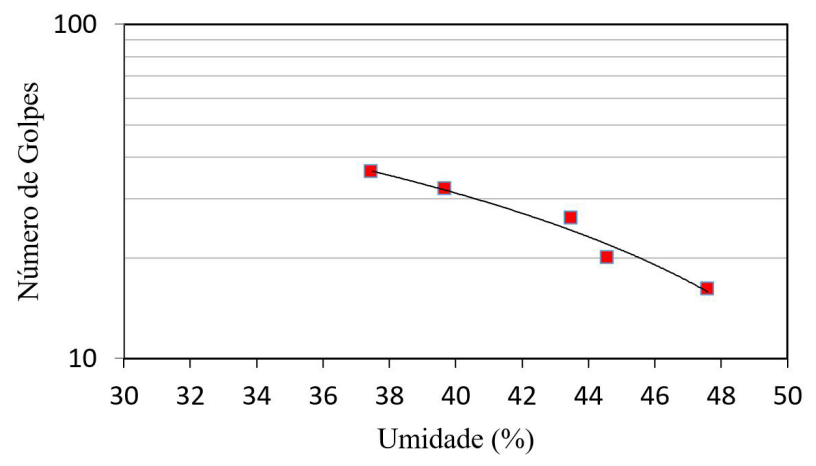

Figura 2. Limite de liquidez do solo. 
De acordo com Pinheiros [12], os valores acima de $45 \%$ para o limite de liquidez e acima de $18 \%$ para índice de plasticidade, são prejudiciais na secagem, no destorroamento e também na mistura dos componentes.

A Tabela 1 apresenta os valores de LL, LP, IP e a quantidade de material passante nas peneiras de abertura $4,75 \mathrm{~mm}$ e $0,075 \mathrm{~mm}$ deste trabalho, e os valores de referência especificados para o solo utilizado na mistura solo-cimento segundo a ABNT NBR 10833:2012 [7]. Na distribuição granulométrica do solo, feita por peneiramento, observou-se que a grande maioria das partículas possuíam entre 0,6 a $0,053 \mathrm{~mm}$. Desta forma, o solo utilizado para o desenvolvimento deste trabalho é considerado adequado para a produção de tijolo solo-cimento.

A Figura 3 apresenta os resultados da análise de difração de raios $\mathrm{X}$ do solo, areia e do cimento. As fases cristalinas identificadas no solo são de quartzo e caulinita, sendo considerado um solo do tipo caulinítico, portanto, possui baixo poder de retenção de água e fraca carga eletronegativa. A caulinita se torna plástica em valores relativamente baixos de umidade, o que explica o limite de plasticidade de $30 \%$ obtido no solo.

Segundo a literatura, a areia é composta predominantemente por quartzo e feldspato [13-15], assim como obtido neste trabalho. As principais diferenças entre o quartzo encontrado na areia para o quartzo encontrado no solo é a forma e o diâmetro das partículas $[13,14]$.

De acordo com a NBR 5733 [16], o cimento tipo CP-V ARI é composto apenas de clínquer, podendo ter até $5 \%$ de material carbonático. $\mathrm{O}$ cimento utilizado neste trabalho apresenta as fases cristalinas de silicato de cálcio e carbonato de cálcio, indicando que o fabricante adicionou calcário na composição do cimento.

\subsection{Imagem do corpo de prova cilíndrico e do tijolo vazado após a cura}

A Figura 4 mostra a imagem dos corpos de prova cilíndricos após prensagem, e do tijolo solo-cimento após a cura em ambiente úmido por 7 dias, ambos com mesma composição. Pode-se observar que após a prensagem o corpo de prova apresenta coloração marrom-acinzentada, característico de massa úmida. Após a cura o tijolo adquire coloração avermelhada característica dos argilominerais presentes na composição do solo.

\subsection{Resistência à compressão simples dos corpos de prova cilíndricos}

A norma ABNT 12025:12 - Solo-cimento - Ensaio de compressão simples de corpos de prova cilíndricos Método de ensaio [6] não determina valores de resistência à compressão simples para corpos de prova (em $\mathrm{MPa})$, pois são analisados de forma comparativa.

No entanto, comparando os resultados de resistência à compressão dos corpos de prova, Figura 5, com a
NBR 8491 [9] (para tijolo vazado de solo-cimento pode-se observar que todos os valores individuais obtidos foram superiores ao indicado pela norma para tijolo solo-cimento (NBR 8491:12 [9]), assim como o valor médio de resistência à compressão simples, que foi de 2,75 $\pm 0,76 \mathrm{MPa}$.

Tabela 1. Granulometria e limites de Atterberg do solo.

\begin{tabular}{lcc}
\hline \multicolumn{1}{c}{ Parâmetros } & NBR 10833:2012 & Resultado \\
\hline $\begin{array}{l}\text { Percentual de Tamanhos de } \\
\text { Partículas do Solo } \leq 4,75 \mathrm{~mm}\end{array}$ & $100 \%$ & $100 \%$ \\
Percentual de Tamanhos de & $10-50 \%$ & Não determinado \\
Partículas do Solo $\leq 0,075 \mathrm{~mm}$ & & \\
Limite de Liquidez & $\leq 45 \%$ & $44 \%$ \\
Limite de Plasticidade & Não definido & $30 \%$ \\
Índice de Plasticidade & $\leq 18 \%$ & $14 \%$ \\
\hline
\end{tabular}

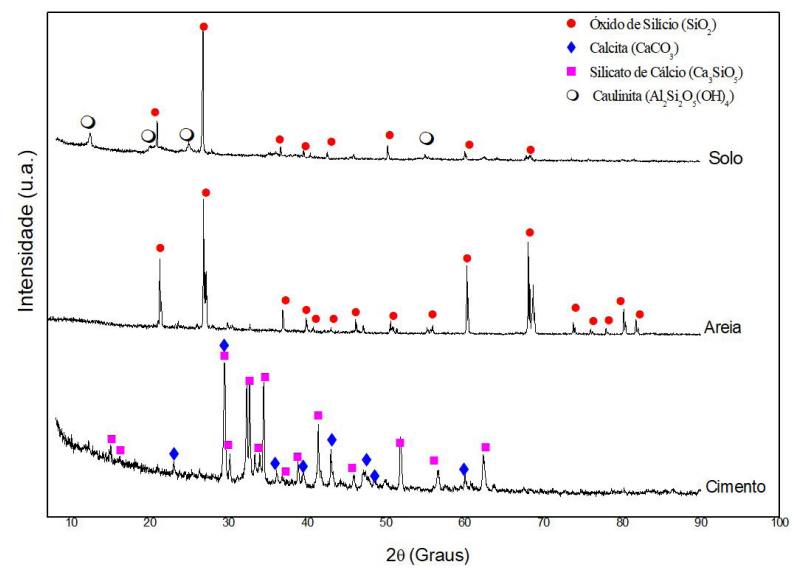

Figura 3. Difratogramas de raios $\mathrm{X}$ do solo, da areia e do cimento.

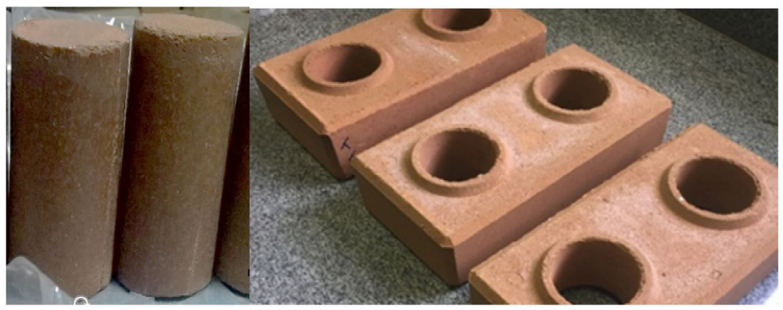

Figura 4. Imagem do corpo de prova cilíndrico após prensagem (à esquerda) e do tijolo vazado (à direita), após a cura.

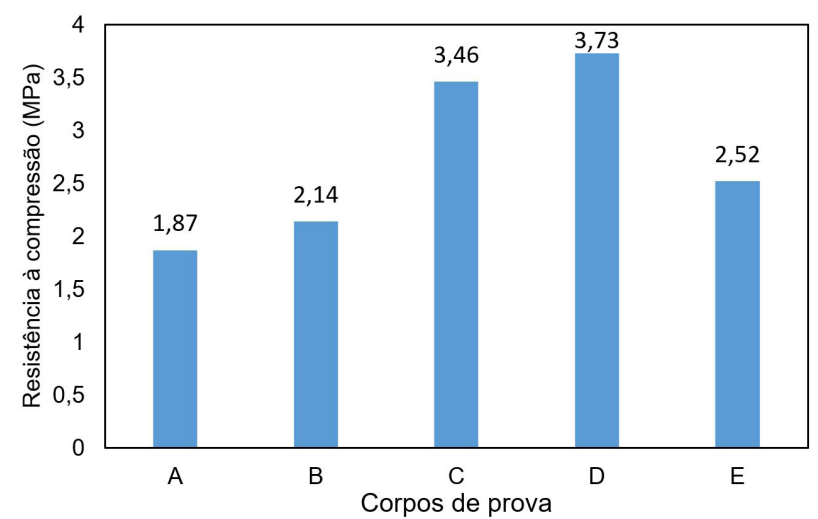

Figura 5. Valores de resistência à compressão simples dos corpos de prova cilíndricos. 


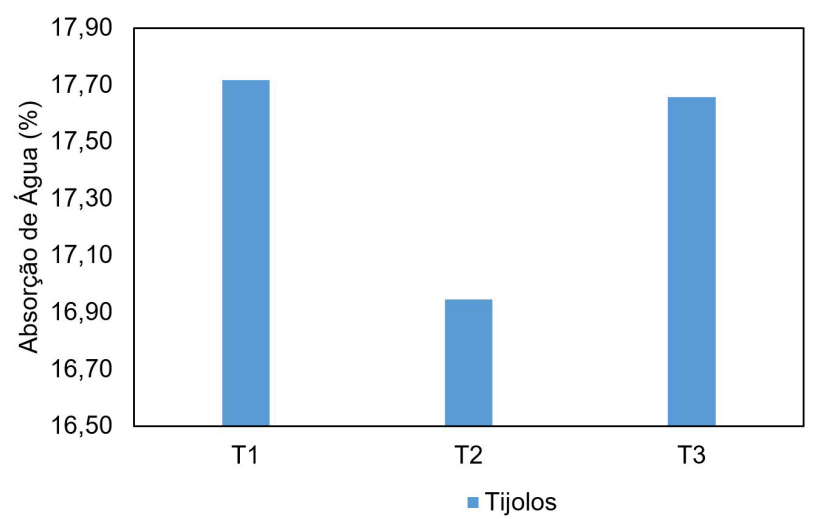

Figura 6. Valores individuais de absorção de água do tijolo solo-cimento.

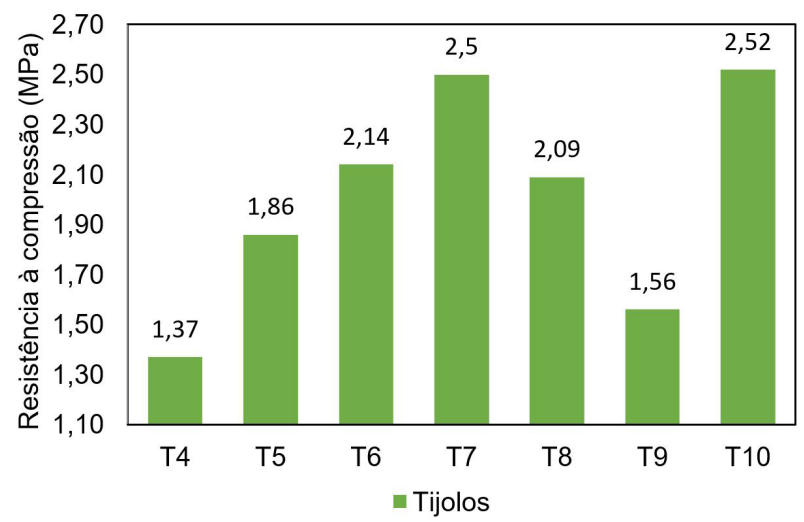

Figura 7. Valores individuais de resistência à compressão simples do tijolo solo-cimento

Os valores de resistência à compressão podem ser influenciados pelo teor de areia na mistura, tipo de solo, granulometria utilizada, forma de compactação, tipo/ marca de cimento, quantidade de água presente na cura ou simplesmente uma variação estatística.

\subsection{Absorção de água e resistência à compressão simples dos tijolos solo-cimento}

A Figura 6 apresenta os resultados do ensaio de absorção de água para os tijolos solo-cimento, é possível observar que os valores individuais estão dentro do estabelecido pela norma, assim como o valor médio que foi de $17,44 \pm 0,43 \%$.

A Figura 7 mostra os valores individuais de resistência a compressão simples dos tijolos solo-cimento, apresentando
2 valores inferiores ao estabelecido pela NBR 8491 [9]. O valor médio da resistência à compressão foi de 2,09 $\pm 0,44 \mathrm{MPa}$, sendo superior ao estabelecido pela referida norma.

Tanto os corpos de prova cilíndricos, quanto as amostras de tijolo solo-cimento apresentaram valores similares de resistência à compressão simples, sendo o primeiro ligeiramente maior que o segundo, indicando que a geometria da peça ou a etapa de capeamento dos tijolos podem interferir no resultado. Os CP's cilíndricos apresentaram resistência à compressão dentro dos valores estabelecidos pela norma ABNT NBR 8491 [9]. Em contrapartida, os tijolos solocimento apresentaram duas amostras com valores abaixo de $1,7 \mathrm{MPa}$, ou seja, não atendem a referida norma.

\section{Conclusões}

Tijolos solo-cimento foram produzidos com solo classificado como caulinítico, constituído em grande parte de areia média e fina, apresentando a maioria do tamanho das partículas entre 0,6 e $0,53 \mathrm{~mm}$, com valores dentro dos esperados para o índice de plasticidade e limite de liquidez (14\% e 44\%, respectivamente).

O resultado de absorção de água dos tijolos solocimento apresentou valores dentro do estabelecido pela ABNT NBR 8491:12 [9] para os resultados individuais e média dos valores.

Comparando os resultados do ensaio de compressão simples dos corpos prova cilíndricos e dos tijolos solo-cimento, com os valores estabelecidos pela ABNT NBR 8491:12 [9], os valores médios para ambos estão dentro do exigido. Porém os valores individuais para o tijolo solo-cimento, duas amostras apresentam resultado abaixo de $1,7 \mathrm{MPa}$, indicando que o formato da peça e a execução do capeamento podem interferir nos resultados do ensaio de compressão.

O tipo de solo utilizado e a composição estudada pode ser aplicado em tijolo solo-cimento, como alternativa para levantamento de paredes de vedação em construção civil.

\section{Agradecimentos}

À empresa ECO REAL pela prensagem dos tijolos solo-cimento e à empresa VERDE EQUIPAMENTOS pela realização dos ensaios de compressão.

\section{Referências}

1 Mesquita ASG. Análise da geração de resíduos sólidos da construção civil em Teresina, Piauí. HOLOS. 2002;2:5865.

2. Lima TV. Estudo da produção de blocos de solo-cimento com matéria-prima do núcleo urbano da Cidade de Campos dos Goytacazes - RJ [dissertação]. Campos de Goytacazes: Universidade Estadual Norte Fluminense; 2006.

3 Grande FM. Fabricação de tijolos modulares de solo-cimento por prensagem manual com e sem adição de sílica ativa [Dissertação]. São Carlos: Universidade de São Paulo; 2003.

4 Souza MIB. Análise da Adição de Resíduo de Concreto em Tijolos Prensados de Solo-cimento [Dissertação de Mestrado]. Universidade Estadual Paulista; 2006. 
5. Associação Brasileira de Normas Técnicas. ABNT NBR 12024: Solo-cimento - Moldagem e cura de corpos de prova cilíndricos - Procedimento. Rio de Janeiro: ABNT; 2012.

6. Associação Brasileira de Normas Técnicas. ABNT NBR 12025: Solo-cimento - Ensaio de compressão simples de corpos de prova cilíndricos - Método de ensaio. Rio de Janeiro: ABNT; 2012.

7. Associação Brasileira de Normas Técnicas. ABNT NBR 10833: Fabricação de tijolo e bloco de solo-cimento com utilização de prensa manual ou hidráulica — Procedimento. Rio de Janeiro: ABNT; 2012.

8. Associação Brasileira de Normas Técnicas: ABNT NBR 8492: Tijolo de solo-cimento - Análise dimensional, determinação da resistência à compressão e da absorção de água - Método de ensaio. Rio de Janeiro: ABNT; 2012.

9. Associação Brasileira de Normas Técnicas. ABNT NBR 8491: Solo-cimento - Requisitos. Rio de Janeiro: ABNT; 2012.

10. Associação Brasileira de Normas Técnicas. ABNT NBR 6459: Solo Determinação do limite de liquidez. Rio de Janeiro: ABNT 2016.

11. Associação Brasileira de Normas Técnicas. ABNT NBR 7180: Solo - Determinação do limite de plasticidade. Rio de Janeiro: ABNT 2016.

12 Pinheiro BJR, Soares DMJ. Utilização de solos arenoso para obtenção de tijolos solo-cimento. Cerâmica Industrial. 2010;15:30-36.

13 Melo VF, Novais RF, Schaefer CEGR, Fontes MPF, Singh B. Mineralogia das frações areia, silte e argila de sedimentos dos grupos barreiras no município de Aracruz, Estado do Espírito Santo. Revista Brasileira de Ciência do Solo. 2002;26:29-41.

14. Senço W. Manual de técnicas de pavimentação. $2^{\mathrm{a}}$ ed. São Paulo: Pini Ltda.; 2001. Vol. 1.

15 Bueno RIS. Aproveitamento da areia gerada em obra de desassoreamento - Caso: Rio Paraibuna/SP [dissertação]. São Paulo: Universidade de São Paulo; 2010.

16. Associação Brasileira de Normas Técnicas. ABNT NBR 5733: Cimento Portland de Alta Resistência Inicial. Rio de Janeiro: ABNT; 1991.

Recebido em: 12 Jun. 2019

Aceito em: 21 Jun. 2020 